\title{
Measuring the opening of national R\&D programs: what indicators for what purposes?
}

\author{
Emilia Primeri ${ }^{1}{ }^{*}$, Emanuela Reale ${ }^{1}$, Benedetto Lepori ${ }^{2}$, \\ Philippe Laredo ${ }^{3}$, Maria Nedeva ${ }^{4}$ and Duncan Thomas ${ }^{4}$ \\ ${ }^{I}$ CERIS CNR, Via dei Taurini, 19 00185, Rome, Italy, ${ }^{2}$ Università della Svizzera italiana, Faculty \\ of Economics, Centre for Organizational Research, CH-6904, Lugano Switzerland, ${ }^{3}$ ARMINES- \\ LATTS, Laboratoire Territoires Techniques et Sociétés, University of Paris Est, 75272, Paris, \\ France and ${ }^{4}$ Manchester Institute of Innovation Research (MIoIR), University of Manchester, \\ M13 9PL, Manchester, UK \\ *Corresponding author. Email: e.primeri@ceris.cnr.it
}

\begin{abstract}
The opening of national research programs has gained importance as a means for increasing international collaboration and for improving the quality and efficiency of scientific research at the national, European, and international levels. The concept of opening refers to the fact that actors who do not belong to a national research space can participate in research funding programs. This complex and multidimensional phenomenon can be operationalized through different measures: the participation of foreign partners in domestic research activities with or without funding, the portability of grants when moving abroad, and agreements for international collaboration (with or without complementary funding). This underlines the importance of having descriptors and indicators, which could provide evidence of different patterns of opening and contrasting perspectives on policy motivations and goals behind opening decisions. The article presents the descriptors and indicators used for exploring opening patterns and logics, which characterize the main project funding instruments in three countries (Switzerland, France, and Italy) on the basis of data collected within the JOREP ${ }^{1}$ project. Preliminary evidence emerging from the three countries surveyed are presented and discussed.
\end{abstract}

Keywords: opening programs; project funding; research policies; internationalization; ERA.

\section{Background}

The opening of national $\mathrm{R} \& \mathrm{D}$ programs in several countries is an important political issue (Optimat Ltd and VDI/VDE/IT 2005), and in the European Commission's view (European Commission 2008) it is a goal to be achieved to reduce the fragmentation of research at the EU level and to support the creation of a truly integrated European Research Area (ERA) (Pérez, De Dominicis, and Guy 2010; European Commission 2008a, 2008b).

'Opening' is considered a key dimension in the establishment of a European market of knowledge, together with the creation of joint programs (Optimat Ltd and VDI/ VDE/IT 2005; Pérez, De Dominicis, and Guy 2010). In fact, most R\&D funding is currently channelled through national programs, meaning the participation of foreign partners in national funding opportunities is important for promoting international research collaboration and increasing the quality of European research via more integration of competences and stronger competition - in other words to move beyond the limitations of 'closed' national research systems (Barré et al. 2013; Nedeva 2013).

Broadly speaking, 'opening' refers to actors who do not belong to a national research system, but nevertheless participate in its research funding programs (Pérez, De Dominicis, and Guy 2010; European Commission 2008c). The question is why and for what purposes national states decide to open their national research programs to foreign participants and under what conditions this occurs in different EU countries. 
Different strategies trigger higher internationalization within national funding instruments, such as strengthening domestic excellence, providing access to the best facilities abroad, attracting the best scientists, preparing for domestic innovations to be marketed abroad, and/or contributing to global problem-solving (Knight 2004; European Commission 2009; Edler and Flanagan 2011). However, the responses of national institutions to pressures for increasing internationalization could be very different according to highly diversified domestic contexts and the national constellation of actors (Knill and Lehmkuhl 2002).

Literature (Lepori et al. 2007; Boekholt et al. 2009) underlines that currently, national ministries and funding organizations play a relevant role in determining flexible internationalization policies and setting up multiple funding measures (e.g. individual grant programs, funding of staff, funding for travel and workshops abroad, international cooperation funding) and already are part of a significant intensification of multilateral and bilateral cooperation in research and higher education policies (Huisman and van der Wende 2004; Langfeldt et al. 2012, European Commission 2012a).

'Opening' also represents a complex and multidimensional issue that can assume different forms above and beyond simply channelling national funding abroad. A multidimensional approach to the analysis of the opening of the largest national research programs (Pérez, De Dominicis, and Guy 2010; European Commission 2011) could help to detect different ways of achieving national goals and objectives.

Despite the obvious complexity of opening issues, studies that address the topic are few and the tools used to collect evidence remain weak and far from complete (Edler and Flanagan 2011).

For instance, many indicators are borrowed from internationalization studies and seem to be more focused on capturing the internationalization features of national policies rather than 'opening' ones. Hence, they often provide insights about researcher mobility or levels of spending for research collaborations, taking into account mostly national research system characteristics that probably have little impact on opening decisions (Pérez, De Dominicis, and Guy 2010). As a consequence, little evidence emerges on patterns of opening that can characterize large national research programs or on contrasting perspectives of policy motivations and goals behind opening decisions. Instead, indicators that could underpin the development of public policies and strategies behind opening decisions could be developed and exploited (Edler and Flanagan 2011, European Commission 2012b).

The aims of the article are-(1) to develop a methodological framework and a set of indicators to characterize the opening of national research programs, (2) to provide preliminary evidence of different patterns of opening across countries using the proposed indicators, and (3) to discuss some tentative interpretations of the observed patterns in terms of national policy configurations, the structure of scientific systems, and the role of national actors in funding decisions.

Our research questions include-What main drivers and actors can be detected behind opening decisions? How relevant is 'opening' within the frame of national project funding instruments? Does opening trigger (further) integration of national research systems?

This article presents a set of descriptors and indicators to capture the different opening patterns of the main research funding programs in Switzerland, Italy, and France. The first section presents the conceptual framework, followed in the second section by the indicators selected for investigating the opening of national research programs. The third section introduces the methodology for the data collection, and in the fourth the results are presented and discussed. In the fifth section final discussion and conclusions are presented.

\section{Conceptual framework}

In a funding and policy context as deeply changed as the European one, several instruments are available for national states and funding agencies to foster international collaborations that are increasingly flexible, intertwined, and go beyond providing funding abroad or encouraging the mobility of researchers (Katz and Martin 1997; Nedeva 2013). We can distinguish at least three types of schemes to support international collaborations: international collaboration agreements, joint agreements (PRO INNO 2009; Lepori, Reale, and Laredo 2014) and the opening of national research programs.

The work focuses on the opening of national research programs to foreign researchers, either to perform research in their own countries or to move to the host country of the program's owner. Almost all European national programs are in principle open to foreign participation, although the rules for participation and funding, as well as actual levels of participation, vary widely from country to country.

Differently from programs that directly fund foreign research organizations (that could be labelled as 'open' programs), 'opening' refers to the possibility that national research programs are open to foreign participants, as applicants or co-applicants, whether or not they receive complementary funding. In the former case, funding schemes are characterized by the effective possibility to transfer money abroad, in the latter several types and degrees of openness are possible, which may or may not include funding flows abroad (Lepori and Reale 2013). Finally we can distinguish between programs targeted to international cooperation, which are based on collaboration agreements (as in the case of bilateral or joint research programs). Our notion of opening is therefore 
much broader than the one used in most previous studies, referring solely to programs directly funding research organizations abroad (European Commission 2008c).

The analysis of the opening of national research programs allows a fine-grained analysis of actual practices, rules, and levels of participation for foreign applicants in large nationally funded research programs. In this analysis, the level of funding transferred abroad is only a limited aspect of the phenomenon and further dimensions are relevant.

We assume that different opening decisions and strategies across countries mostly depend on highly diversified policy goals and objectives pursued by the main national actors and their roles in national funding systems.

Opening policies and strategies, as well as objectives pursued when opening national research programs to non-national participants, vary across countries and are shaped by the interests and scientific priorities of strategic actors (government, funding agencies, and performers). Therefore, we can expect 'strong' and 'light' forms of opening nationally, with both displaying different levels and degrees of opening.

Strong forms of opening allow foreign organizations to have an official role in the research project and allow for the transfer of funding abroad, or funding that follows researchers when they move abroad (portability). Strong forms of opening can be expected in only a few cases, for instance when reciprocity is ensured through the mutual opening of national programs or via agreements and collaboration schemes between funding agencies (i.e. the Lead Agency Agreement collaboration scheme) that constitute shared rules about scientific quality and funding commitments. Equally, strong forms of opening might occur when major national scientific priorities are at stake, meaning the opening of national research programs to foreign collaboration is a better option then keeping programs national. Strong forms of opening could then be highly selective, and improving existing joint or bilateral program schemes, instead of opening national research programs, could represent a better option for national actors.

Light forms of opening are the majority and mainly represent a way for national actors and policies to comply with EU policies and pressures for increasing integration and coordination of national programs and instruments. These forms are expected, especially in the case of institutional pressure towards opening, as they are less costly than stronger forms of opening. Here the label of 'opening' is often used to indicate the possibility for larger collaborations at the international level, which are allowed by national programs. A gap between formal opening (mostly limited to formal rule provisions) and effective forms of opening (still envisaging different modes or levels of openness) is likely to be observed. Additionally the higher the internationalization of the national research system and the national scientific community, the more effective the forms of opening will be. Opening is also likely in its stronger forms, when a high complementarity among national research programs emerges, when requisite competences are not available nationally (e.g. this is the main criteria for the Swiss open program Sinergia), when the appropriation of scientific results is limited (as is the case for larger networks of collaboration), or where benefits from collaboration are expected to be captured mostly at the national level.

We can expect different patterns and levels of opening according to major differences across countries with respect to the conditions under which non-nationals have access to national funding opportunities. Thus, opening might be shaped by (1) pressures from the scientific community (more internationalization of the community might imply more opening); (2) specific policy goals (for instance the development of collaborations or strategic alliances); and (3) the tendency to conform national funding instruments to those used in other European countries.

Opening might also depend upon the particular actors involved in policy-making, namely policy actors and independent funding agencies. Funding agencies are not simply executive organizations, rather they are often positioned between political grant givers (the State) and receivers (beneficiaries) so that they benefit from some autonomy in the policy-making decision process. Thus, policy actors may be tied more to a territoriality principle and be more reluctant to opening (especially when resources have to go abroad), whereas funding agencies might be more open. This is especially true for Research Councils, because of the strong connections they have with the expressed needs of the research community. These factors can then be related to how characteristics differ among the countries examined.

Following this conceptual framework, we developed a set of indicators to capture different facets and dimensions of opening, or degrees of openness, and then attempt to link the evidence available to national research system characteristics and the role of national actors in funding policies.

\section{Indicators}

To analyse different dimensions and levels of opening, we developed three sets of descriptors and two indicators.

Our first set of descriptors characterizes different forms of opening, regarding modes and conditions of participation, the time of opening, and grant portability.

A mode of participation refers to the way participation is enacted by foreign researchers (i.e. whether or not a formal role is played in the project, either as coordinator or partner, with or without funding for the activities performed). Here we can distinguish between: (1) international cooperation including the participation of foreign 
partners in project activities through regular exchanges of information and results, but without a formal role in the project; (2) participation with a formal role, including specific duties within the project (e.g. as a co-applicant or subcontractor), and formal responsibilities but no research funding (e.g. expenses for meetings and travel only); and lastly (3) the participation of foreign partners abroad with formal roles, and also the eligibility to receive research funding.

The time of opening refers to the moment during the life cycle that the opening occurs (e.g. at the point of application, of funding decisions, or later opening through the involvement of foreign partners).

The possibility to move project funding abroad following researcher migration, i.e. the portability of a grant, is considered because it is an important influence on researcher mobility, and it also highlights differences in the organization of national funding systems, as well as the differing cultures and missions of funding agencies.

A second set of descriptors provides insights on the different patterns of opening of the programs (including countries the program is open to, the year in which the program was opened to foreign participants, and to which beneficiary sectors foreign collaborations are open).

Our third set of descriptors refers to those characteristics that may facilitate foreign participation, which includes the availability and accessibility of information concerning national programs in the English language and the possibility to submit proposals in a foreign language.

Finally, the actual level of opening of the countries we surveyed is analysed through two indicators, namely:

- Share of projects with at least one foreign partner (thus considering only collaborations in which foreign partners have an official role);

- Share of projects with foreign participants receiving funding compared with the whole project funding volume.

The Table 1 below summarizes our descriptors and indicators:

The Table 2 below outlines characteristics of light versus strong forms of opening according to the proposed set of descriptors and indicators presented above.

Thus, our proposed descriptors and indicators would allow us to distinguish between different modes of participation (considering the type of collaboration, the role of foreign partners, and the possibility to receive or to move funding) and the level of openness, while highlighting differences among formal and actual levels of opening.

\section{Methodology}

Our data come from a pilot analysis of large national research programs in three western European countriesSwitzerland, France, and Italy. The work does not investigate the transfer of personal grants to foreign applicants, thus personal grants transferred to foreign researchers who are not residents of the country where they have applied for the grant, but it considers the opening of large national research programs towards foreign research organizations. We define large national research programmes according to their financial volume and their importance in the national funding landscape (i.e. the coverage and representativeness with respect to the national project funding landscape). Using a pilot exploration of the opening of national research programs, both qualitative and quantitative information collected by national experts within the JOREP project was used. Qualitative information, mainly official documents available in the public domain concerning the programs' aims and objectives, budget, and rules for participation, as well as calls issued when available, have been used to provide insights about opening features and patterns. Quantitative data have also been collected by national experts or estimations were provided when data were missing. Problems of consistency of data across countries based on differences in the national funding systems were considered (i.e. typology of funding agency), and shortcomings with respect to the availability of information for the descriptors indicated have been also discussed in the analysis in the following chapters (i.e. years of opening information). Data collected proved the feasibility of a pilot exploration of opening patterns of largest national research programs.

\subsection{General sampling strategy}

The perimeter of national programs to be considered for the analysis was defined according to the following criteria: (1) all largest national research programs were included, taking into account the financial volume of the programs and their coverage with respect to the national project funding volume (e.g. their share of national project funding according to OECD/NESTI project); (2) the coverage of different research fields was considered, so to exclude programs only devoted to funding specific research fields; (3) programs funding research abroad were included; (4) mobility-only schemes or personnel grants schemes were excluded; (5) the year of reference for selecting and analysing the programs was the year 2009 .

Fifty-two programs were considered for the analysis, which support research, innovation, and other activities related to research (e.g. PhD scholarships). Programs overlapping with 'brain gain' national initiatives (e.g. the 'Rientro dei Cervelli' action in Italy) or aimed only at attracting foreign talented researchers and $\mathrm{PhDs}$ to work in national research institutions (i.e. very similar to mobility programs) were excluded (as were programs only funding travels abroad or envisaging subcontracting of specific services from foreign providers).

We covered several scientific domains via our selected national research programs (Figure 1). Generally, 
Table 1. Descriptors and indicators on opening

\begin{tabular}{|c|c|c|}
\hline Descriptor/indicator & Details & \\
\hline Countries opened & - ERA countries /Worldwide/towards some countries only & Patterns of opening \\
\hline Year of opening & - The year programs opened to foreign collaboration & \\
\hline Beneficiaries & - Beneficiary sectors & \\
\hline Time of opening & $\begin{array}{l}\text { - Application and funding stages } \\
\text { - Later opening }\end{array}$ & Dimensions/forms of opening \\
\hline Modes of participation & $\begin{array}{l}\text { - Participation without a formal role in the project } \\
\text { - Participation with a formal role (foreign partner, foreign } \\
\text { coordinator) } \\
\text { - Foreign partner not receiving research funding } \\
\text { - Foreign partner receiving research funding (for research per- } \\
\text { formed in the within of the project) } \\
\text { - Availability of funding to support international cooperation } \\
\text { (travels, exchanges) }\end{array}$ & \\
\hline Portability of grant & - Possibility of funding to follow researcher (if moving abroad) & \\
\hline $\begin{array}{l}\text { Language barriers and information } \\
\text { affordability }\end{array}$ & $\begin{array}{l}\text { - Availability of information in foreign languages } \\
\text { - Call text in English } \\
\text { - Proposal submission in English }\end{array}$ & Opening facilitations \\
\hline $\begin{array}{l}\text { Level of opening of national research } \\
\text { programs }\end{array}$ & $\begin{array}{l}\text { - Share of projects with partners abroad } \\
\text { - Share of projects with foreign participants receiving funding as } \\
\text { a percentage of the project's entire funding volume }\end{array}$ & Actual level of opening \\
\hline
\end{tabular}

Table 2. Forms of opening

\begin{tabular}{|c|c|c|}
\hline \multirow{2}{*}{$\begin{array}{l}\text { Descriptors } \\
\text { Patterns of opening }\end{array}$} & \multicolumn{2}{|c|}{ Forms of opening } \\
\hline & $\begin{array}{l}\text { Strong } \\
\text { opening }\end{array}$ & $\begin{array}{l}\text { Light } \\
\text { opening }\end{array}$ \\
\hline Wide & & $X$ \\
\hline Ad hoc & $X$ & \\
\hline \multicolumn{3}{|l|}{ Dimensions of opening } \\
\hline Foreign partner official status & $X$ & $X$ \\
\hline $\begin{array}{l}\text { Funding to foreign applicants/ } \\
\text { portability }\end{array}$ & $X$ & \\
\hline Funding for international cooperation & & $X$ \\
\hline Later opening & & $X$ \\
\hline $\begin{array}{l}\text { Opening since application/funding } \\
\text { stages }\end{array}$ & $X$ & \\
\hline \multicolumn{3}{|l|}{ Opening facilitations } \\
\hline Information availability & $X$ & $X$ \\
\hline Language barriers & $X$ & $X$ \\
\hline \multicolumn{3}{|l|}{ Level of opening } \\
\hline $\begin{array}{l}\text { Share of projects with foreign } \\
\text { participants }\end{array}$ & & $X$ \\
\hline $\begin{array}{l}\text { Share of projects with foreign partici- } \\
\text { pants receiving funding }\end{array}$ & $X$ & \\
\hline
\end{tabular}

programs considered cover the general advancement of knowledge, although some countries had a concentration of topic programs appearing to be more strategic and serving national interests (e.g. Health and Environment). Moreover, Swiss programs do not address specific scientific priorities and are mostly oriented towards the general advancement of knowledge and wide scientific coverage (all categories). French programs are split into different scientific domains, reflecting the Agence Nationale de la Recherche's (ANR) organization with separate thematic programmes by topic, instead of a single program divided in subareas or subprograms. In the French case, Health and Environment are the main domains covered with the Explorations and Exploitation of the Earth. For Italy, there are a few specific topics, including industrial production and technology, and social sciences and humanities.

\subsection{Program characteristics by country}

Slightly different choices drove the selection of programs that were included in our analysis. In the Swiss case the main instruments for project funding at the national level were considered, corresponding to three-quarters of total national project funding. The Swiss Sinergia is the only program that can be labelled as 'open', as it has the possibility to involve foreign organizations as official partners that are entitled to their own budget.

For Italy the main programs funded by the Ministry of Research (MIUR) were included, although complete data on project funding were not available. For some programs (e.g. the Italian Program for the Diffusion of Scientific Culture) we considered whether the program supports and funds research only or rather a broad range of 'related' activities (e.g. conferences, meetings, travels) to try to depict to what activities 'opening' possibilities apply.

In France, only national programs funded by the ANR were included, as they display - at least in their categorization by topic-some interesting opening features. 


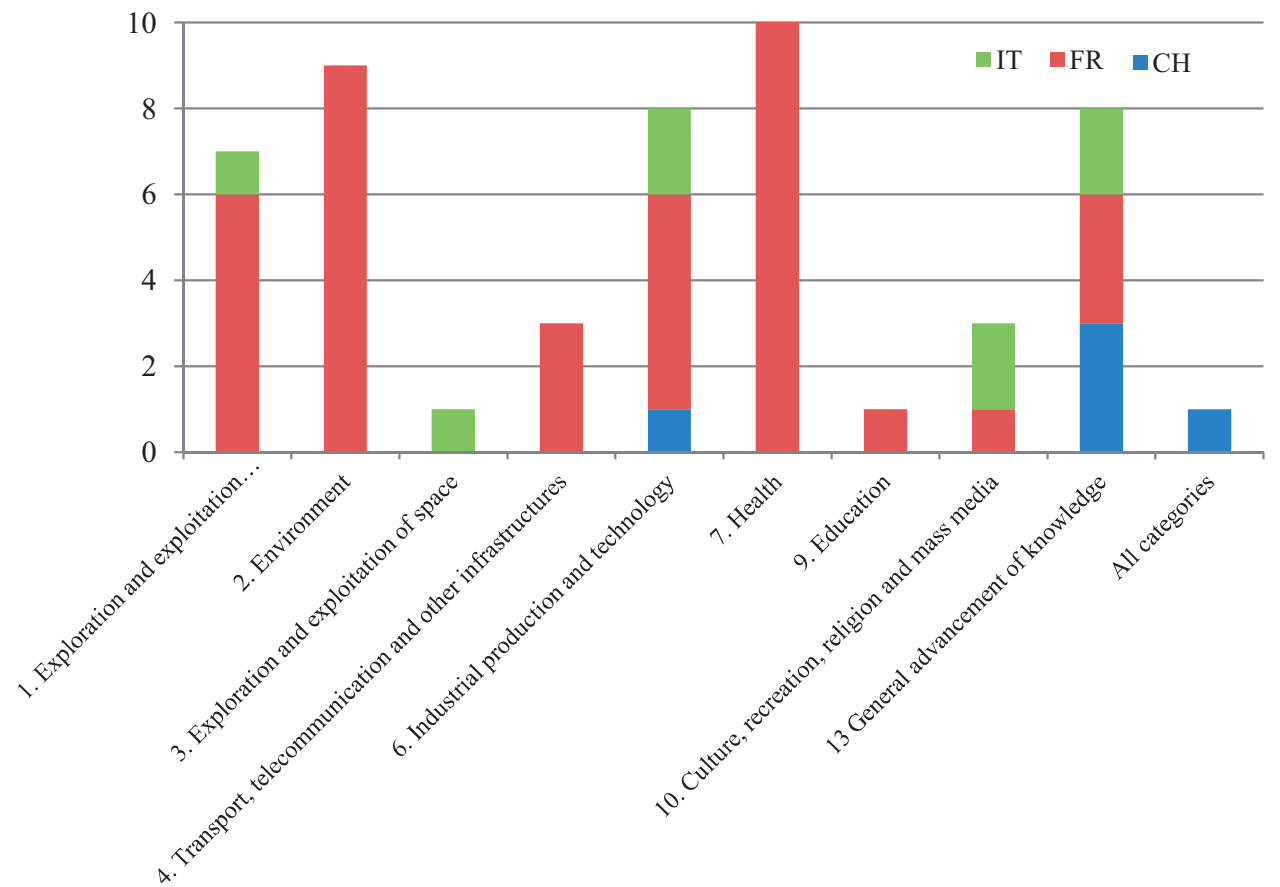

Figure 1. Topics covered by national programs selected.

Table 3. Programs for the pilot analysis on opening

\begin{tabular}{|c|c|c|c|}
\hline $\begin{array}{l}\text { Programs details and } \\
\text { countries }\end{array}$ & France & Italy & Switzerland \\
\hline Programs included & $\begin{array}{l}\text { Thematic programs by the Agence } \\
\text { Nationale de la Recherche ( } 39 \\
\text { thematic programs by field). }\end{array}$ & $\begin{array}{l}\text { FAR (Fund for the promotion of } \\
\text { Research) } \\
\text { FIRB (Basic Research Investment } \\
\text { Fund) } \\
\text { FIRB (Futuro nella Ricerca) } \\
\text { FIT (Fund for Technological } \\
\text { Innovation) } \\
\text { Program for the diffusion of sci- } \\
\text { entific culture (Law 6/ 2000) } \\
\text { Funding of 'Program } \\
\text { agreements'. } \\
\text { PNRA-National Program of } \\
\text { Research in Antarctica } \\
\text { National Space Plan }\end{array}$ & $\begin{array}{l}\text { Swiss National Science } \\
\text { Foundation (SNF): Research } \\
\text { projects. National research } \\
\text { programs. National compe- } \\
\text { tence centres in research. } \\
\text { Sinergia. } \\
\text { Swiss Innovation Agency: } \\
\text { cooperation projects with } \\
\text { the industry. }\end{array}$ \\
\hline Involved agencies & $\begin{array}{l}\text { Agence Nationale de la Recherche } \\
\text { (ANR) }\end{array}$ & $\begin{array}{l}\text { Ministry of Research (MIUR); } \\
\text { Ministry of Economy; } \\
\text { Italian Space Agency }\end{array}$ & $\begin{array}{l}\text { Swiss National Science } \\
\quad \text { Foundation (SNF); } \\
\text { Swiss Innovation Agency. }\end{array}$ \\
\hline Total budget 2009 & 392 mio. Euros & 137 mio. Euros & 426 mio. Euros \\
\hline $\begin{array}{l}\text { Share of national project } \\
\text { funding }\end{array}$ & N.A. & $\begin{array}{l}\text { N.A. but the largest instruments } \\
\text { are covered. }\end{array}$ & 76\% (OECD NESTI) \\
\hline
\end{tabular}

Moreover ANR programs are divided into three categories: national programs open to international cooperation, national programs with explicit incentives to collaborate with foreign partners, and national-oriented programs.

The Table 3 below summarizes the main details from the programs we addressed:

\section{Opening of national research programs: evidences beyond definitions}

\subsection{Dimensions of opening}

The key dimensions considered here are (1) the time of opening, (2) the modes of participation of foreign 
Table 4. Conditions of participation for foreign researchers (number of programs)

\begin{tabular}{|c|c|c|c|c|c|c|c|c|c|c|c|c|}
\hline & No & Cond. $^{a}$ & Yes & No & Cond. $^{a}$ & Yes & No & Cond. $^{\mathrm{a}}$ & Yes & No & Cond. $^{a}$ & Yes \\
\hline $\mathrm{CH}$ & 5 & 0 & 0 & 1 & 3 & 1 & 1 & 3 & 1 & 1 & 0 & 4 \\
\hline FR & 0 & 0 & 39 & 0 & 37 & 2 & 39 & 0 & 0 & 0 & 0 & 39 \\
\hline IT & 5 & 2 & 1 & 3 & 0 & 5 & 7 & 0 & 1 & 1 & 0 & 7 \\
\hline
\end{tabular}

Source: Reale et al., JOREP Final Report, European Commission 2013.

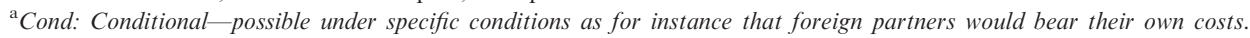

research organizations, and (3) the possibility for funding to follow the researchers if they are relocated abroad.

For the time of opening, little information emerges from the official documents. It seems that opening takes place mostly at the application stage, when the consortium is set up for proposal submissions. Later opening is possible, according to the project's needs or the specific activities to be performed (e.g. the Italian program for the promotion of the scientific culture).

On modes of participation (Table 4), our data show a range of participation opportunities in national research programs. By looking at the role foreign partners can have in national research programs, the coordination of a foreign institution is generally not allowed in Swiss and Italian programs, albeit with some exceptions (e.g. the program FIRB Futuro in Ricerca, after the recent application as coordinator presented by a researcher of a foreign institution to perform research in their 'home' university). For a few French programs, mostly based on bilateral agreements, foreign coordination is possible, at least formally, although in practice little evidence emerges. In very few cases, for example the very large French-German security program, having a foreign coordinator is mandatory.

Differences across countries also emerge for participation with official 'partner' status. We consider 'official partner status' as the possibility for foreign research organizations to be project applicants or co-applicants with or without coordination possibilities. Other types of participation, i.e. participation as a subcontractor or an appointment as an independent expert, are not discussed here, as it is mostly of no significance when capturing the opening features of national research programs. Rather it is interesting to consider whether an official status is recognized or not or when this depends on specific conditions often detailed in the programs of the calls for funding activities. In all the French ANR programs, research organizations from other countries can have an official status and be recognized as full research partners (if they bear their own costs).

For Italian programs, generally they indicate a possibility to involve foreign institutions through agreements or signature of letters of intent or memorandums of understanding. This applies in particular to programs that support the creation of networks between national and international institutions (e.g. the FIRB and PNRA-National Program of Research in Antartide). In the Swiss case, there is a tendency towards the opening of large programs managed by the Swiss National Science Foundation (SNF), when specific competences not available nationally are required. Generally an official status is fully recognized for foreign partners when a bilateral agreement has been signed. Swiss Innovation Agency programs focusing on the development of the Swiss economic space are not open to foreign partners.

Our data show that cooperation funding is generally possible, whereas funding for research to foreign institutions remains generally excluded. We distinguish here between funding received by foreign organizations for research activities performed within the project, and funding availability in programs to support international collaboration and thus devoted towards funding activities related to research, such as travel, workshops, and joint meetings. The only exceptions are Italy (FIRB programs) and Switzerland, which has the possibility to fund research abroad, but this is mostly conditional. For instance the Swiss program Sinergia features funds transferred by the Swiss main applicant. This practice is also the case for investigator-driven projects with lead agency agreements (Germany and Austria). The so-called money follows cooperation line of these agreements specifies that when the partner abroad has a limited share of the budget, it is directly funded by the SNF (whereas if the share is larger, the lead agency model is applied). French programs clearly state that foreign organizations participating as the main applicants or as coordinators must bear their own costs. Interestingly, the majority of French programs considered specify that funding can be provided only to French organizations located in France, international laboratories associated with French institutions, and French institutions located abroad. When key scientific priorities concern national interests, collaborations are promoted and supported, for instance as seen above, granting foreign partners with an official status as coordinator. 


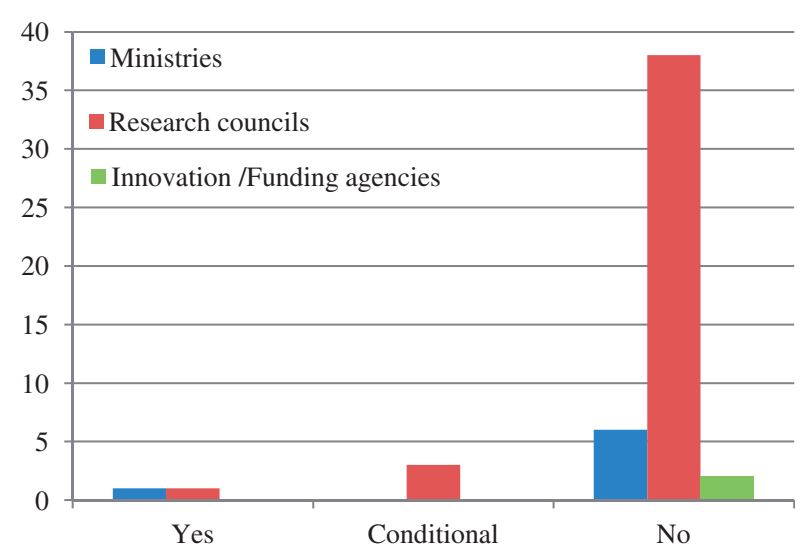

Figure 2. Foreign partners research funding.

Data (Figure 2) also confirm that foreign partners' research funding generally is not allowed, and it can be conditional only when research councils manage programs.

Finally, looking at the possibility for researchers to move their funding abroad (grant portability) major differences emerge. These are mainly related to characteristics of the national regulations concerning public funding, and to different cultures and missions of funding agencies.

In Italy, grant portability is not possible. Activities must be performed nationally, sometimes even in the region where the grant holder is located. For Switzerland, grants from the Swiss National Science Foundation are given mostly to individual researchers. They are portable, although under the condition that the project has already started when the researcher moves (decisions are made by the SNF on a case-by-case basis). Swiss Innovation Agency grants, however, are usually not portable, as these funds are strictly related to promoting the national economic space in Switzerland, and the cooperation between national public research organizations and national industry.

In France, grants are attributed to the institution and not to the researcher, so they are not portable if researchers move abroad or become employed in a foreign organization because ANR does not fund foreign organizations. However, the grant is portable if the principal investigator moves to a research organization abroad on secondment from his/her institution for a limited length of time; the same is true if they move to a French research organization located abroad (provided that the original research organization agrees, and additional employability and nationality criteria apply).

\subsection{Patterns of opening}

Looking at the countries in which programs are open, we distinguish among three main categories: (1) programs

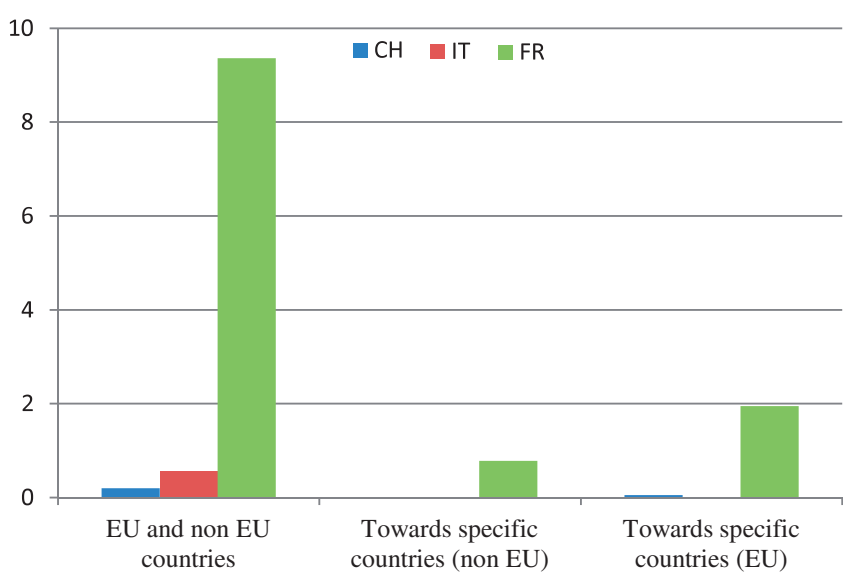

Figure 3. Opening towards EU and non EU countries.

open towards specific EU countries, (2) programs open towards specific non EU countries, and (3) programs which allow international collaboration with foreign partners without specification (EU and non EU countries). Our data (Figure 3) show that most of the programs are generally open to this third category of wide collaboration at the international level.

In some cases, opening towards specific countries applies, including when specific sectors of collaboration are concerned (e.g. energy, biotechnologies); when crossborder collaborations are signed under reciprocity conditions (i.e. the lead agency model in the Swiss case); or when bilateral agreements or joint collaboration schemes determine how international collaboration is framed ${ }^{2}$.

Information on the year of opening was missing for most of the programs we studied. The scant data available suggest this is a recent issue, as the majority of programs were open to international collaborations mainly from around 2008/09.

For instance, Swiss programs only opened to foreign collaboration recently: the program Sinergia was established in 2008 only and the first lead agency agreements were signed in 2009 (and further agreements have been signed in 2012 and 2013). The same holds true for France, although many programs, often recently launched, were open to foreign collaboration soon after their inception when the first calls for proposals were issued. Moreover, some of the programs we analysed were at least open in principle from the beginning, although a 'real' opening has not occurred in most cases (for example Italian programs with FIRB Futuro in ricerca were excluded to a very limited extent). Thus generally, the opening of national programs appears to be an emerging issue for national research programs.

With respect to program beneficiaries, our data show that they are, for the most part, open to both the public and private sector, with the exception of all Swiss programs (that give no funding to private companies) and the Italian FIRB (public sector only). In a few cases, 
mainly when firms are the main beneficiaries, it is specified that there must be scientific benefits from international collaboration for national industries.

\subsection{Opening facilitations}

Descriptors mostly refer to factors that could be considered as facilitating the access and the participation of foreign organizations to domestic programs. These encompass mostly the availability of information in English and the possibility to submit proposals in a foreign language. The information can be very detailed, clearly specifying the rules and limitations of foreign collaboration (high), while in other cases it can be quite general (medium), or provide no information at all (low) ${ }^{3}$.

Data (Figure 4) show differences among the three countries in relation to the use of foreign languages and the availability of information on international participation.

The availability of information for French programs is generally quite high, although call texts are often in French. The main exceptions are programs that specifically refer to relevant bilateral agreements for collaboration in their calls for proposal. In these cases, a document in English is attached which specifies collaboration rules according to the agreement signed (e.g. the MatetPro program whose 2012 call for proposal includes a dedicated document for Franco Norwegian collaborative projects, albeit addressing only a few research areas compared to the scope of the whole program). To facilitate access to information, an English section of the ANR website is available. In Switzerland, all information and calls for proposals are available in English. The SNF website also includes a specific section clearly explaining the various opportunities for international collaboration within national programs.

On the opposite end of the spectrum, in Italy the use of the national language in calls for proposals is widespread. There is very limited information on participation opportunities for foreign partners, with a few exceptions (e.g. FIRB). Often information can be retrieved only as a

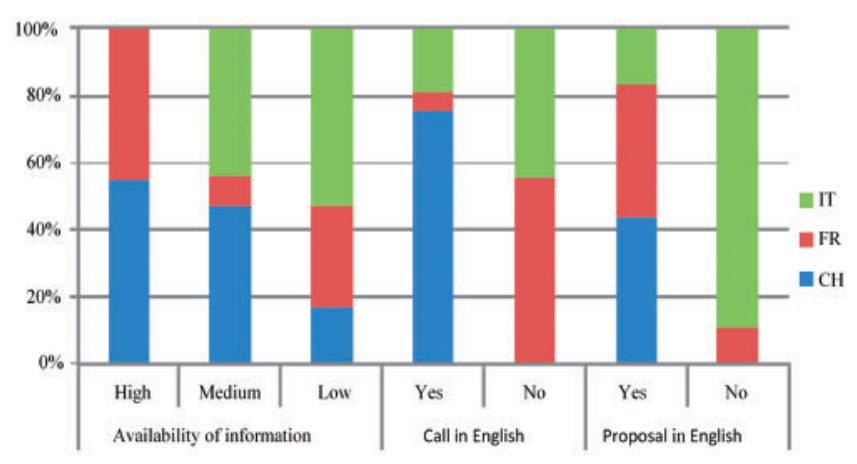

Figure 4. Facilitations of opening. generic recommendation within the call, or in official documents that establish the programs.

Regarding the possibility to submit proposals in English, in the Swiss case this is always possible. This is mainly due to the very high level of internationalization of Swiss research organizations and their scientific community, as well as the widespread practice of Swiss researchers experiencing and conducting international refereeing (in English). For the French case, submitting proposals in English is also possible in almost all programs. Here this is mainly related to the internationalization of the reviewing process instead of the internationalization of the projects themselves. In Italian programs, the possibility to submit a proposal in English is quite limited (it was possible in principle for only three of the eight Italian programs we surveyed).

\subsection{Level of opening}

Measuring the level of opening for national programs is quite difficult. Data are scarce concerning foreign participants. Details about the share of project funding devoted to international collaboration are rare, and often may not be collected or specifically disaggregated within funding data. In the table below (Table 5) our estimates are based on data collected mostly through official program documents, and are presented as ranges to account for data limitations.

We have used two indicators here, namely:

- Share of projects with at least a foreign partner having an official role;

- Share of projects with foreign participants receiving funding, compared to the whole project funding volume.

We were able to distinguish three cases. First, there are cases in which opening provisions exist but are not used in practice, such as for the share of foreign participants in the programs, compared with the budget amount for France. Second, it could be the case in countries where foreign collaborations within national programs are few and with a very limited budget (as in the Italian case). Third, there are cases in which participation from abroad is regular (as is the case for Switzerland and its Sinergia program in particular).

Generally very few projects involve foreign participants, with the exception of some very small programs (e.g. French programs on very specific topics whose actual level of opening in fact should not be overestimated) even when programs formally allow the participation of foreign partners. The share of projects with foreign participants receiving funding is generally low if compared with the volume of project funding, showing that funds from abroad are generally limited. These results are not surprising. Rather they confirm that foreign participation remains an option to be exploited in very few cases, when 
Table 5. Foreign participation in national programs

\begin{tabular}{|c|c|c|c|c|c|c|c|}
\hline \multirow{2}{*}{$\begin{array}{l}\text { Programs info } \\
\text { Number of programs }\end{array}$} & \multicolumn{7}{|c|}{ Share of foreign participations to national programs } \\
\hline & $0 \%$ & $<1 \%$ & $<5 \%$ & $<10 \%$ & $<20 \%$ & $>20 \%$ & NA \\
\hline $\mathrm{CH}$ & 2 & 2 & 0 & 0 & 0 & 1 & \\
\hline FR & 17 & 0 & 3 & 7 & 2 & 4 & 6 \\
\hline IT & 0 & 0 & 0 & 0 & 1 & 0 & 7 \\
\hline Total & 19 & 2 & 3 & 7 & 3 & 5 & 13 \\
\hline \multicolumn{8}{|c|}{ Programs budget (mio. Euros) } \\
\hline $\mathrm{CH}$ & 118 & 275 & & & & 32 & \\
\hline FR & 175 & & 42 & 70 & 16 & 20 & 68 \\
\hline IT & & & & & 4 & & 132 \\
\hline Total & 294 & 275 & 42 & 70 & 21 & 52 & 200 \\
\hline
\end{tabular}

Source: Reale et al., JOREP Final Report 2013.

Number of programs by $\%$ of project with foreign partners and total budget of the programs in each category (mio. Euros)

national participants feel they can benefit the most by foreign contributors. In this case, funding moving abroad is possible, although it remains quite rare.

\subsection{Opening of national research programs: what insights from the data?}

The analysis of data and information from the program documents collected allows a brief analysis of the opening patterns of the countries considered. For Switzerland, the opening of national research programmes does not represent a separate issue but it developed in the frame of project funding activities. This emerges also from the highly diversified types and number of funding agreements and schemes which support international collaboration (i.e. Lead Agency Agreement, 'Money follow cooperation' agreement and 'Money follows research' agreement). At present, funding abroad seems to be limited and possible in very few cases, for example in SINERGIA through the Swiss principal investigator. Moreover, opening mainly concerns investigator-driven programs and, to a very limited extent, programs addressing industry support. For the former, grants are allocated mostly to individual researchers to support bottom up interdisciplinary and disciplinary projects, as well as to improve networking capacities, with grants being generally portable. This is not the case for industry collaboration projects supported by the Swiss Innovation Agency, as its mission is strictly related to the promotion of the national economic space in Switzerland.

As for the Italian programs analysed, opening does not represent a specific issue, rather it is recalled in the calls as an invitation to involve foreign researchers and research organizations to improve the quality of research to be performed. Opening thus seems to represent a strategic option to be exploited by national applicants rather than a mandatory requirement. An example of this is the Italian Program for the diffusion of scientific culture (funding of 'Program agreements'). Differently from what happens with bilateral agreements, opening represents an opportunity for improving project quality or strengthening networking among similar institutions when the cognitive needs and aims of international collaborations are not identified ex-ante by the program.

As for French programs, especially recent ones, they always include the possibility to involve foreign partners, although no funding can be provided abroad and they must bear their own costs. In the frame of national programs, bilateral agreements for collaboration are sometimes recalled and are regulated by ad hoc rules of participation with respect to generic possibilities of participation by foreign organizations. This can be observed especially when programs are considered highly strategic and serve national scientific and economic interests. This is the case for instance in the ANR security program between France and Germany (Concepts, Systems and Tools for Global Security - CSOSG) where strategic and cognitive motivations emerge to be relevant, although twofold. The cognitive motivations of both countries are mentioned in most of the calls and documents related to this program. However, in practice, the program mainly aims at boosting the strategic supremacy of the 'French-German couple' in the security domain in Europe, giving access to knowledge and skills that are not available nationally, while protecting national leadership on strategic issues.

The same emerges in relation to topics such as Sustainable Energy, the IT sector, and Engineering. The ANR's annual programming to address these issues is technology-oriented and very strategic at the economic level. It aims at boosting national skills first, using foreign competences when available. To that respect it could be argued that opening represents an opportunity in the frame of large national programs to boost bilateral cooperation on highly diversified but strategic topics, without setting up ad hoc bilateral or collaborative programs, to serve national knowledge and competition needs. 


\section{Discussion and conclusions}

\subsection{The phenomenon of opening of national research programs}

The 'opening' of national research programs is a complex phenomenon that can range from initiating international collaboration, to providing full funding of research abroad (European Commission 2011). In between, different dimensions of opening and levels of openness can be distinguished: they include the encompassing participation of foreign partners in domestic research activities (both with and without funding), grant portability when researchers move abroad, and opportunities for international collaboration (with or without complementary funding). The indicators and descriptors we have developed and tested are valuable when attempting to position the opening of national programs.

Differences across the mentioned dimensions mostly mirror the differences of policies, needs, and goals pursued by the main national actors in the national research and funding context when opening national programs to foreign research organizations.

Thus, compared with a restrictive definition, which focuses merely on funding flows abroad, which could lead to the conclusion that this phenomenon is relatively marginal and/or limited to specific cases (e.g. bilateral agreements or opening agreements towards specific countries based on reciprocity criteria), our broader definition of opening here includes more nuanced dimensions, and has the potential to lead to far more interesting and useful results.

\subsection{National characteristics of opening}

Our analysis demonstrated very diversified modes, strategies, and levels of opening, ranging from keeping programs mostly national (with very limited levels of opening), 'opening' them to international collaboration through bilateral/multilateral agreements mainly to serve national scientific needs, and putting in place soft or strong forms of opening. Data also show highly diversified opening patterns depending on the type of funding agencies in charge of programs at the national level (Ministries vs. Research councils) and related to national research system characteristics and the scientific priorities pursued at the national level. Although our sample could be improved by including a larger set of countries and programs to draw general conclusions, we nevertheless can discuss some interesting insights.

Italy shows a limited level of openness of national research programs, with no distinction according to program type and scientific priorities addressed. Factors that should enable foreign participation appear to be generally weak (visibility of information and use of foreign language). Most of its programs are open at least in principle, but lack effective measures to support this aim (e.g. an official status for foreign organizations in programs). The only exception is the FIRB program and the FIRB Futuro in Ricerca (the former treats opening mainly within the frame of existing international and bilateral agreements and the latter mainly addresses individual researchers' collaborations opportunities).

France has a diversified attitude towards opening. Although its main research programs show an effective level of opening (e.g. foreign research organizations are entitled to an official status as coordinator), and measures are adopted to improve foreign participation (e.g. the possibility to submit proposals in English), the effectiveness of opening is hampered by a lack of appropriate facilitating resources (e.g. the availability of calls in English) and funding measures (e.g. grant portability and transfer of funding abroad). Programs considered strategic for national research priorities (e.g. in the field of energy) largely remain national. When specific scientific topics are considered to be better addressed at the international level, however, the French case is either generally open to wide international collaborations or to collaboration with specific, relevant, partner countries. Here collaboration mostly takes place once again within the frame of existing international collaboration agreements (e.g. bilateral or joint agreements). The observed pattern mostly reflects a 'formal' opening, however, only with real and stronger opening measures put in place where national needs and interests must be satisfied.

Switzerland, among the countries we analysed, has the only program that is directly funding research abroad, Sinergia. It allows funding foreign partners to perform research abroad (albeit via a funding transfer through the Swiss principal investigator). Switzerland generally shows an effective level of opening. All of their programs are open, at least in principle, and they provide adequate instruments to support foreign collaboration (e.g. official status for foreign organizations, high visibility of programs, information through the widespread use of English, grant portability). An exception is found with programs where industries are the main target sectors, managed by the Swiss Innovation Agency. Here the Agency's mission is strictly related to the promotion of the national economic space. Even in that case, the internationalization of the economy pushed the government to a more flexible position, and from 2014, the Swiss innovation agency is formally allowed to sign agreements for participation of foreign partners to innovation projects when this is in the interest of the Swiss economy.

However 'strong' the forms of opening that emerge in the Swiss case, most seem to be enacted when reciprocity and mutual opening are ensured (e.g. the case of Lead Agency agreements) or when scientific competences are not available nationally and need to be found abroad (e.g. where the main criteria for the Sinergia program to allow foreign participation and funding becomes relevant). 
Moreover, a higher degree of opening can be detected for investigator-driven research programs in Switzerland, which could benefit most from wider collaboration instead of applied research programs, which are mostly context- and nationally related.

Switzerland's case also seems to reflect a national research system and a scientific community that is highly internationalized, and where national funding programs are mainly in charge of a dynamic and responsive funding agency, the SNF.

\subsection{Political structure and opening patterns}

The different role of actors in national funding systems seems to affect opening policies, decisions, and features. Ministries appear less responsive than national Research Councils (e.g. ANR/SFN vs. MIUR) when deciding internationalization policies and opening policies in particular. In the Italian case, national ministries are mainly in charge of the largest national research programs and, in a very limited capacity, the opening measures in place are formal ways to comply with increasing internationalization and collaboration pushes.

In France, the organization of the ANR by scientific domain allows the agency (although to a limited extent given national regulations) to develop diversified strategies to improve international collaboration that is consistent with the needs and priorities expressed by the scientific community. In the Swiss case, internationalization policies are mostly reflected in the opening features of national research programs, with a few exceptions where domestic industrial interests are concerned. Moreover, effective measures are also put in place (e.g. existence of different grant portability schemes).

Therefore, we can argue that where national funding systems are more flexible and diverse decision centres exist, highly diversified strategies of opening can emerge, although within a frame of similar national normative contexts and funding rules.

Secondly, the role played by performers (the scientific community) is also relevant, in addition to opening decisions and implementation (for example, measures, beneficiaries, and the sectors concerned). Scientific communities can be more or less effective at the national level according to their relevance, their particular strengths in the decision-making process, and the level of internationalization they themselves display, which is exemplified for instance by the number of international co-publications (e.g. according to 2012 SCImago data, in Switzerland $64 \%$ of documents include at least one foreign affiliation, $49 \%$ in France, and $41 \%$ in Italy), the level of participation in internationally funded programs (EUFPs in particular; in Italy this is quite relevant, although with limited success if we consider that funding received under EUFP7 corresponds to $8 \%$ of total funds assigned, compared for instance to the French percentage of roughly $11 \%$; MIUR 2012), and more generally, the capacity to attract international funding (as it could emerge for instance from the amount of funding received by international collaborations with universities and research organizations).

Finally, opening features are quite heterogeneous and reflect clear country-specific patterns, such as their preexisting orientation towards basic research and the public sector in Switzerland, towards industrial research in Italy (at least when considering the program budgets), or the organization by research topics adopted by the French ANR. The goals of funding schemes also clearly matter in determining the level of opening, so that it depends on whether they concern research- driven projects or projects mainly for the benefit of industrial partners.

As suspected, such differences are relevant, as they help to shape the rationale for opening according to the overall goals and orientation of the programs in relation to the scientific sectors addressed, the relevance of the programs, and the types of beneficiaries involved.

\subsection{Relationship between opening and bilateral programs}

Our study confirms that strong forms of opening are an exception, as transferring funding for research abroad remains almost limited, mainly for national political reasons. Often legal frameworks within which research programs operate explicitly, forbid the transfer of funds to non-residents or rules for foreign partners' participation are not fully evident and clear. Moreover, the lack of reciprocity in collaborations also emerges as an important feature to foster the opening of national research programs. This might be expected when mutual opening (including making financial resources available) is ensured. Reciprocity then becomes an important factor in enabling stronger forms or rather actual forms of opening to be put in place by national states. This, as summarized by Figure 5, can lead to differing strategies for opening national programs to foreign participation: the switch to bilateral programs, as is the case with ANR collaborations, and to collaboration models such as the SNF

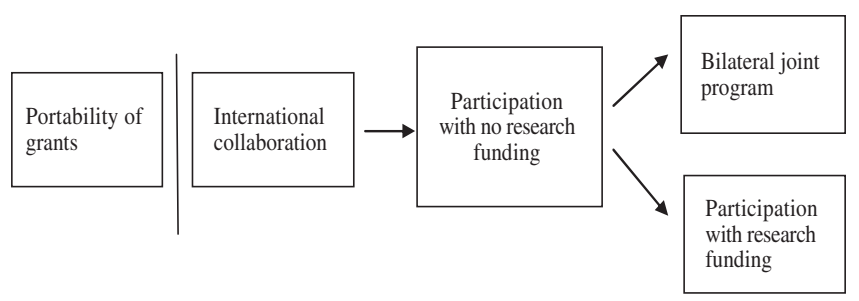

Figure 5. Dimensions and levels of opening of national programs.

Source: Reale et al., JOREP Final Report 2013. 
lead agency agreement. Here we can suggest that international collaboration based on funding programs might in the future follow two main streams. On the one hand, European-based joint programs, where funding resources and program design is decided at the supra-national level, and on the other hand, an 'opening' of national programs which is, when it involves the funding of foreign partners, transformed into bilateral and coordinated agreements on the basis of the initiatives led by national funding agencies (Lepori et al. 2014).

\section{Conclusions}

The current study focused on the different patterns and levels of opening that large national research programs, in the largest context of project funding instruments, can display and on the policy motivations of the main national actors behind opening decisions.

Our results underline that policies and rationales that drive opening decisions are often highly diversified according to national research and funding system characteristics as well as to major national policy and funding actors' needs, the role they play within national research systems, and the goals and objectives they pursue when opening national research funding programs. In fact, national actors mostly shape policy decisions and funding choices, putting in place highly diversified strategies and policies with respect to internationalization and the opening-up of national research programs. Also opening seems to be strictly related to the level of internationalization of the national research systems. In so far, national systems, although facing the same external isomorphic pressures for increasing internationalization and coordination of nationally rooted policies, put into effect different institutional arrangements and funding decisions (Lepori et al. 2007; Svanfeldt 2009; Nedeva 2013).

By looking at the drivers and actors behind opening decisions, opening represents a policy priority especially when it serves to fill national scientific gaps or when R\&D capabilities are weak. The main driver of opening to national research programs appears to be the possibility they provide to serve national policy goals to improve research capabilities and assets by strengthening collaborations with foreign researchers and research organizations. This is mostly the case for investigator-driven research where foreign collaboration is considered important. Opening mostly seems to serve national scientific community needs and interests, especially when national scientific priorities are at stake and there is the need to maintain a leading position in the field through international collaboration at the national level, at the EU-level, or in the international arena (European Commission 2007). Thus, no specific drivers and rationales for opening national research programs emerge, rather opening represents a different option to serve national scientific needs with respect to international collaborations or bilateral cooperation agreements.

Although increasing cooperation at the international level and strong coordination of nationally rooted research policies are encouraged and advised, as it emerges in particular from EU policy documents, national answers are highly diversified according to national research system characteristics and to selective behaviours of national actors when opening national research programs. Two interesting observations emerge here. First, an increasing 'agencification' characterizes several policy decision processes, providing national agencies (i.e. public organizations) with greater autonomy. This makes them more susceptible towards opening, compared for instance, with national ministries whose activities and decisions are more closely tied to national priorities. Second, based on our observations, national agencies could become more strategic actors in national research contexts, deciding on the basis of national interests and taking into account the views of the scientific community on the specific needs of various disciplinary fields.

With respect of the relevance of opening in the frame of existing national project funding instruments, our analysis displays that some levels of opening increasingly characterize large national research programs, those constituting the bulk of national research funding. Therefore, this phenomenon represents a highly relevant evolution in the making of the European Research Area, which is not fully represented when one only takes into account the amount of funding flows abroad (as with a more limited definition of 'opening').

We also encountered anecdotal evidence that opening is in most cases recent, and it represents a widespread phenomenon, albeit generally the level of openness remains quite limited, with 'lighter' forms of opening being more common than 'stronger' forms. It could be argued that opening represents a way for national states to respond to pressure for increasing the coordination of national research policies and international collaboration, although this is currently being accomplished mainly via formal rather than effective engagements, especially in financial terms.

To conclude, our data suggest that looking to the agency level is a relevant approach when analysing the 'opening' features of national research programs, as is looking at the science dynamics and specificities of scientific domains covered by the programs.

Analysing the 'opening' features of national research programs - rather than just a limited focus on funding flows alone-would appear to be an approach that can be adopted to improve our knowledge about strategic issues, such as the strategic role played by funding agencies within the public research funding system. 


\section{Acknowledgement}

For this work, the authors acknowledge support from the European Commission through the JOREP study (Contract No. RTD/DirC/C3/2010/SI2.561034). We acknowledge the contribution and the information provided by the European Commission that has kindly agreed to the dissemination of the results of the study. The authors would like to thank the national experts involved in the JOREP data collection. The authors would also like to thank Michael Wise for assistance in editing and proof-reading the text. The views expressed in this article are those of the authors and do not necessarily reflect the opinion or position of the European Commission.

\section{Notes}

1. JOREP (Joint and Open Research Programmes) is a study funded by the EC under the Contract No. RTD/ DirC/C3/2010/SI2.561034

2. Examples are the French program CP2DCoopération bilatérale France and Finland or the French-Norwegian agreement for proposals presentation within the national calls for proposals 'Nanotechnology and Nano-systems -P2N', and 'Materials and processes for high performance products-MATETPRO' or the Italian FIRB program open to foreign collaborations in 2005 on the base of bilateral and international agreements signed by the MIUR and foreign HEIs.

3. The public availability of information on foreign participation opportunities has been judged by national experts on the basis of program documents publicly available.

\section{References}

Barré, R., Henriques, L., Pontikakis, D. and Weber, K. M. (2013) 'Measuring the integration and coordination dynamics of the European Research Area,' Science and Public Policy, 40: 187-205.

Boekholt, P., Edler, J., Cunningham, P. and Flanagan, K. (2009) 'Drivers of International Collaboration in Research' In: Report to European Commission, DG Research, Technopolis BV, April 2009, The Netherlands.

Edler, J. and Flanagan, K. (2011) 'Indicator needs for the internationalization of science policies', Research Evaluation, 20/1: $7-17$.

ERA Expert Group. (2008) Opening to the World: International Cooperation in Science and Technology. Brussels: ERA Expert Group.

European Commission. (2007) The European Research Area: new perspectives. Green paper, COM (2007), 161, Brussels See http://ec.europa.eu/research/era/pdf/era-greenpaper_en. pdf.

(2008) 2020 Vision for the European Research Area, See http://ec.europa.eu/research/era/2020_era_vision_en.html.

(2008a) 'Optimising research programs and priorities', Report of Amanatidou, EUR 23324. Luxembourg Office for Official Publications of the European Communities. (2008b) 'A more research-intensive and integrated European Research Area Science', Technology and Competitiveness key figures report 2008/2009. Brussels: Office for Official Publications of the European Communities.

- (2008c) ERA Expert Group. Opening to the World: International cooperation in Science and Technology, Brussels. - (2009) 'Drivers of international collaboration'. In: Final report, Brussels.

. (2011) Innovation Union Competitiveness Report. Brussels: European Commission.

- (2012a) 'International Cooperation in Science, Technology and Innovation: Strategies for a Changing World,' In: Serger, S. S. and Remoe, S. (eds) Report of the Expert Group Established to Support the Further Development of an EU International STI Cooperation Strategy. Luxembourg: Publications office of the European Union.

European Commission. (2012b) 'A reinforced European Research Area partnership for excellence and growth'. In: Communication from the Commission to the European Parliament, the Council, the European Economic and Social Committee and the Committee of the Regions, COM(2012) 392 final.

. (2007) 'The European Research Area: new perspectives. Green paper,' COM p. 161. Brussels. <http://ec.europa.eu/ research/era/pdf/era- greenpaper_en.pdf $>$.

Huisman, J. and van der Wende, $\bar{M}$. C. (2004) 'On cooperation and competition. National and European policies for internationalisation of higher education' In: $A C A$ Papers on International Cooperation. Bonn, Germany: Lemmens.

Katz, J. S. and Martin, B. R. (1997) 'What is research collaboration?', Research Policy, 26: 1-18.

Knight, J. (2004) 'Internationalization remodeled: Definition, approaches, and rationales,' Journal of Studies in International Education, 8: 5-31.

Knill, C. and Lehmkuhl, D. (2002) 'The national impact of European Union regulatory policy: three Europeanization mechanisms,' European Journal of Political Research, 41/2: 255-80.

Langfeldt, L., Godø, H., Gornitzka, A. and Kaloudis, A. (2012) 'Integration modes in EU research: Centrifugality versus coordination of national research policies,' Science and Public Policy, 39: 88-98.

Lepori, B. et al. (2007) 'Indicators for comparative analysis of public project funding: Concepts, implementation and evaluation,' Research Evaluation, 16/4: 243-55.

Lepori, B., Reale, E. and Laredo, P. (2014) 'Logics of integration and actors' strategies in European joint programs,' Research Policy, 43/2: 391-402. http://dx.doi.org/10.1016/j. respol.2013.10.012.

Lepori, B. and Reale, E. (2013) Handbook on data collection on Joint and Open Research Programmes (JOREP), European Commission, Directorate-General for Research and Innovation. <http://ec.europa.eu/research/innovation-union/ pdf/jorep_hanbook.pdf $>$.

MIUR Italian Ministry of University and Research. (2012), Data about Italian Participation to EUFP7 Programme. DG IR, Ufficio III http://www.ricercainternazionale.miur.it /media/9122/settimo_programma_quadro_dati_partecipazione italiana.pdf.

Nedeva, $\bar{M}$. (2013) 'Between the global and the national: Organising European science,' Research Policy, 42: 220-30.

Optimat Ltd and VDI/VDE/IT. (2005) 'Examining the Design of National Research Programs,', Final Report prepared for the European Commission DG Research (Directorate M2) Prepared by Optimat Ltd, www.optimat.co.uk, VDI/VDEInnovation + Technik GmbH, www.vdivde-it.de.

Pérez, E. S., de Dominicis, L. and Guy, K. (2010) Developing the European Research Area: Opening-up of National $R \& D$ 
Programs and Joint R\&D Policy Initiatives, JRC Scientific and Technical Research series. Luxembourg: Publications Office of the European Union.

PRO-INNO Europe. (2009) Making public support for innovation in the EU more effective Lessons learned from a public consultation for action at Community level, Paper $\mathrm{n}^{\circ}$ 13, Commission Staff Working Document SEC (2009) 1197 of 09.09.2009, Luxembourg: Publications Office of the European Union, 2009.
Reale, E. et al. (2013) 'Investments in joint and open research programmes and analysis of their economic impact (JOREP) Final report,' European Commission, Directorate-General for Research and Innovation. <http://ec.europa.eu/research/innovation-union/pdf/jorep final_report.pdf $>$.

Svanfeldt, C. (2009) 'A European research area built by member states?'. In: Delanghe, H., Muldur, U. and Soete, L. (eds) European Science and Technology Policy: Towards Integration or Fragmentation? Cheltenham, UK: Edward Elgar. 